\title{
Analysis of tsunami hazards by modelling tsunami wave effects
}

Tiziana Rossetto, William Allsop, Dave Robinson, Ingrid Chavet \& Pierre-Henri Bazin

Reproduced from:

Flood Risk Management - Research and Practice Proceedings of FLOODrisk 2008

Keble College, 0xford, UK

30 September to 2 October 2008 


\title{
Analysis of tsunami hazards by modelling tsunami wave effects
}

\author{
Tiziana Rossetto \\ University College London, Civil, Environmental \& Geomatic Engineering London, UK
}

William Allsop

Coastal Structures, HR Wallingford, Wallingford \&

University Southampton, UK

Dave Robinson

Coastal Structures, HR Wallingford, Wallingford, UK

Ingrid Chavet

University College London, Civil \& Environmental Engineering, London, UK

Pierre-Henri Bazin

Coastal Structures, HR Wallingford, Wallingford, UK

Ecole Central Lyon, France

ABSTRACT: Tsunamis are an ever present risk to coastlines around the world, but many aspects of tsunami behaviour are unclear or little understood, so require significant further investigation. This paper presents the development of a new physical modelling facility to model and study scaled tsunami waves, and their effects, in a 2-D flume.

The concept design of the new facility is explained and the preparatory analysis that was performed to confirm the feasibility of the design. An explanation is given of the main causes of building damage when a tsunami strikes and several available methods for limiting that damage. Finally, the testing that is to be performed later in 2008, using the tsunami generator, is described and the future plans for the facility are set out.

\section{INTRODUCTION}

Tsunamis are water waves caused by earthquakes, underwater landslides, volcanic eruptions or major debris slides. Tsunamis can be highly destructive natural disasters, so protecting structures and people from their impact has become a growing area of interest throughout the world.

Earthquakes in subduction zones are notorious for generating Tsunami. Plate boundaries deform abruptly and displace the overlying water (see Figure 1). This creates two sets of (very long) waves that travel away in opposite directions: one set with a leading crest and one with a leading trough. For local seismic activity, these waves radiate out, decreasing in magnitude with increasing distance from the source. For extended subduction movement (line slip), the tsunami front may however be relatively straight, and reductions in magnitude with distance may be very much less.

In deep water, tsunami waves have relatively small heights (typically $0.5-2 \mathrm{~m}$ ), but very long wavelengths (say 5-20 km). As these waves enter the shallower waters of coastal areas, their length reduces sharply and their wave height increases dramatically. The resulting steep waves may cause violent wave impacts onto shoreline structures, and the very long wave lengths may lead to extensive inundation inland.

Tsunami risk to coastal areas can be considered to be composed of two main elements: the tsunami hazard, and the vulnerability of the natural and built environment to this hazard. Good understanding, representation and modelling of both elements are necessary in order to produce useful and reliable damage scenarios and loss estimates. Governments require such estimates to make decisions as to if and how to intervene to mitigate potential tsunami induced losses, and where to locate critical facilities or emergency resources to ensure effective post-disaster relief and recovery, see Figure 2. There are however, large gaps in knowledge in both risk components. For example, from the hazard perspective there are large uncertainties regarding nearshore processes of tsunami, inundation prediction and tsunami loading on buildings. From the vulnerability standpoint it is not yet clear 

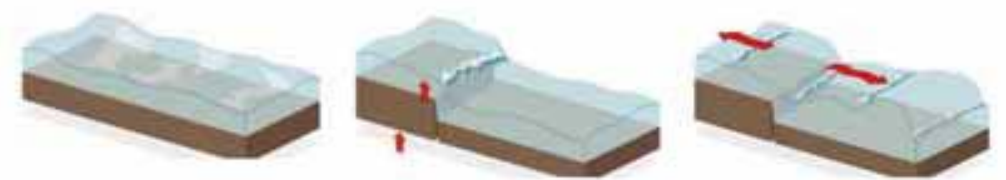

Figure 1. How an earthquake can generate a Tsunami, from "Tsunami Disaster", BBC News.
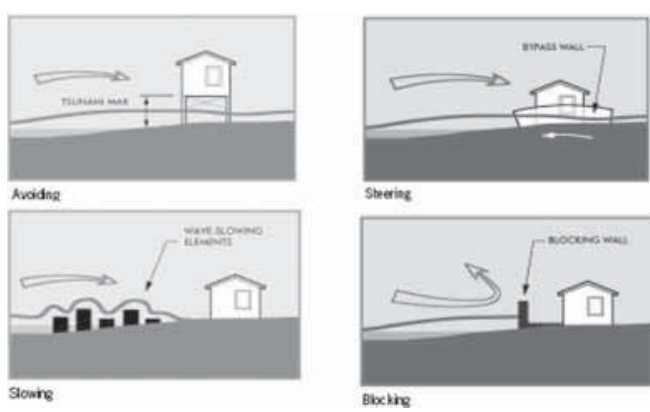

Figure 2. Suggested methods to defend against tsunami damage (after Univ Hawaii).

how different structural types perform under tsunami actions, nor to what extent different coastal protection measures mitigate tsunami effects.

This paper provides an outline of the "Violent Flows" project being undertaken by HR Wallingford (HRW), Arup and UCL's Earthquake and People Interaction Centre's (EPICentre). This project looks to answer a number of the following questions: given a certain tsunami, bathymetry and beach topography:

- Can we predict the onshore flow?

- What are the tsunami loads on coastal structures?

- Are existing guidelines (e.g. FEMA55) adequate?

- What are the criteria of design acceptability?

In particular this paper describes the first phase of the project, which looks to answer the first two questions above through the development of a physical modelling facility capable of generating a train of tsunami within a 2-D flume at a scale of between 1:75 and $1: 150$.

\section{MODELLING TSUNAMI ONSHORE FLOW}

A characteristic of Tsunami waves is their very large ratio of wavelength to wave height. Even the biggest Tsunami may only have a wave height of about $5 \mathrm{~m}$, whilst their wavelength could be over 10 or $20 \mathrm{~km}$. As these waves move into coastal and near-shore depths, they shoal up dramatically, creating a hazardous wall of turbulent water.
It is often mistakenly assumed that Tsunami waves occur singularly. Actual events often generates a series of Tsunami, which interact significantly as they propagate shoreward. This is important when studying the effect of Tsunami onshore, as the combined effect of multiple waves can be devastating. A further misnomer is that they are always preceded by a negative wave or trough. In reality, most subduction driven tsunami generate a trough on the over-riding side of the slip, but not on the other side.

Generation and propagation of Tsunami have been simulated by various numerical models, from source to nearshore. The critical gaps in knowledge are in the propagation of Tsunami in the nearshore region, across the shoreline, and inland. These flow processes cannot yet be simplified sufficiently for numerical models as there are complex interactions with beaches, sediment, coastal defences, and then around buildings. These processes can however be simulated in physical models, but correct generation of the Tsunami is essential, including in some instances the characteristic draw-down of the preceding trough.

Some academic studies have been performed to model physically generation and propagation of large waves, but they have mainly concentrated on idealised cnoidal and solitary waves (Hammock, 1972; Goring, 1987; Synolakis, 1987), or have attempted to model landslide generated Tsunami by dropping or sliding a large object into the water (Wiegel, 1960).

\section{THE HRW TSUNAMI GENERATOR: CONCEPT DESIGN AND SPECIFICATION}

Physical modelling of wave-structure processes is commonly used to analyse armour movement, compapnent forces, wave overtopping, and related responses where the complexity of the fluid flow processes are too complex to model numerically. The major problem with physical modelling of Tsunami waves is the generation of the full length of the wave. Conventional paddle generators simply do not have the stroke to reproduce the entire wavelength, which can be of orders $1-10 \mathrm{~km}$ at prototype scale. This project aims to design and construct the first Tsunami Generator that will be capable of generating a complete Tsunami within a physical model. It adapts the principles 


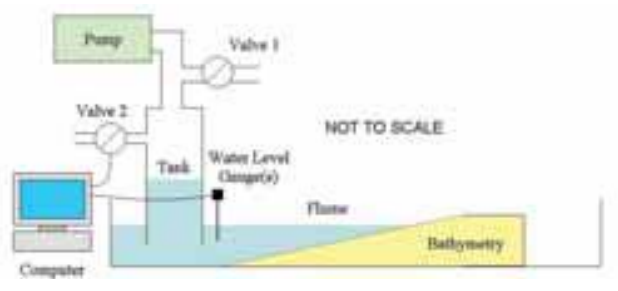

Figure 3. Conceptual design of the Tsunami Generator.

of HRW's pneumatic tide generators with the intention to run tests at scales between 1:75 and 1:150.

Generation of the full wavelength is important to be certain of fully capturing the forces that can act on coastal structures, buildings and vegetation as the Tsunami propagates onshore. These forces can be divided into three stages: momentum-driven forces imparted by the wave front; drag forces (mostly) from the associated onshore flows that follow the wave front; and (drag) force exerted as the wave retreats and returns seaward. This last force can be aggravated by debris suspended in the return flow.

The proposed Tsunami Generator is designed along the principles of the Pneumatic Tide Generator previously built and used by HR Wallingford. Such tide generators are particularly useful in moving large amounts of water in and out of a model in a controlled manner. This ability makes this type of tide generator ideally suited to the generation of Tsunami because they are capable of creating the unusually long wavelengths that characterise these waves, and can generate both crest and trough components.

The Tsunami Generator is under construction at the time of writing this paper (June 2008). When in use, it will sit at the end of one of the $45 \mathrm{~m}$ long 2dimensional wave flumes within the Froude Model Hall at HR Wallingford. When not in use the Tsunami Generator can be lifted out of the flume and stored, allowing the Wave Flume to be used for its main purpose. The concept design is shown in Figure 3, and a schematic drawing of the Tsunami Generator in a wave flume in Figure 4.

It is intended that the Tsunami Generator will be capable of generating Tsunami at a scale factor between 1:75 and 1:150, using undistorted Froude scaling. The time period of a Tsunami is rather shorter than of a tide. The main alteration to the tide generator will therefore be to change the control system to operate at increased speed. A more modern (and quieter) vacuum pump has been acquired, and control valves and their servo motors may need to be modified, as the required operating regime will extend the previous requirements.

As for most such physical modelling, the bathymetry in the test flume will be formed by cement mortar

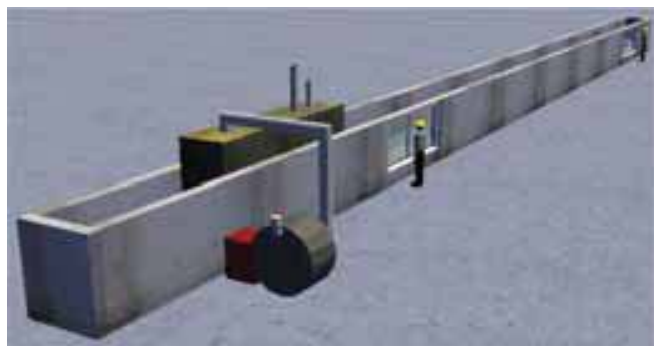

Figure 4. Scematic of the Tsunami Generator in a wave flume.

overlying compacted fill. The bathymetry profile that will be used during the initial testing has not yet been chosen, but the provisional assumption is that it will feature a beach slope of approximately 1:100 slope over the main upper section. Seaward of this beach, it may require a steeper approach slope, say 1:20 to fit into the main body of the flume. This will allow for some onshore topography to be included in the model and for an onshore tank to be placed for the collection of inundating water.

\section{PREPARATORY ANALYSIS}

\subsection{Desk calculations}

Operation of the conceptual design of the Tsunami Generator has been checked using desk calculations to give confidence in its feasibility. The desk calculations were carried out in two phases. Phase 1 estimated the speed of response and explored potential oscillations (overshoot) in the tank water level once the required tsunami has been generated. These gave the designers suggestions as to how potential oscillations might be minimised.

Once the major part of a required tsunami wave crest has been generated, the water within the test flume will need to fall through the equilibrium position under control to a wave trough (i.e. avoiding any further unwanted wave generation). As the control mechanism is air, and therefore rather elastic, it is likely that the falling water column will oscillate in the control tank. Estimating any overshoot will help establish how accurately the trough and tail end of tsunami waves can be modelled. The two drivers for oscillations in the water level are:

- The surface level velocity in the tank at the end of wave generation.

- The time lag between valve movement and tank water level response.

The drivers for these oscillations depend on kinetic and potential energies within the water column. 
Once equations to model these oscillations were defined, the key parameters were varied to calculate their respective influences on the overshoot magnitude, and period.

The calculation was set up, and time lag and water level velocity were then varied independently and their respective effect on the overshoot and required stopping offset were output.

The tsunami generator must be able to draw up (and release) water from the test flume under the control of the vacuum pump and 2 valves (see Figure 3 ). The pump must have a suitable performance envelope and the valve control system must be capable of moving the valves at sufficient speed and accuracy. Phase 2 of the calculations therefore involved estimating the performance that will be required from the pump and valve control system.

To do so required assumptions on the tsunami waves to be generated. It was assumed that idealised solitary or N-waves might be required, but it was also noted that a potentially useful time series of three waves had been recorded during the Boxing Day tsunami in

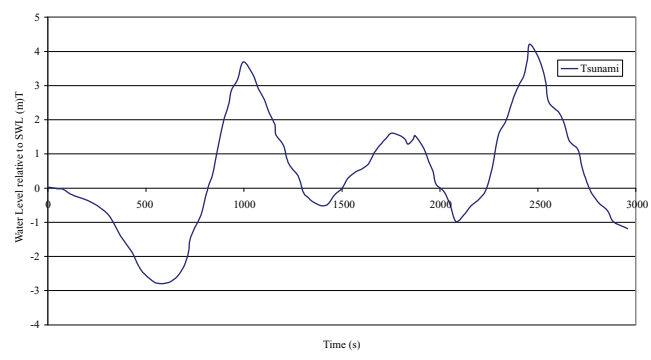

Figure 5. Time series of water surface elevation taken on the yacht Mercator.

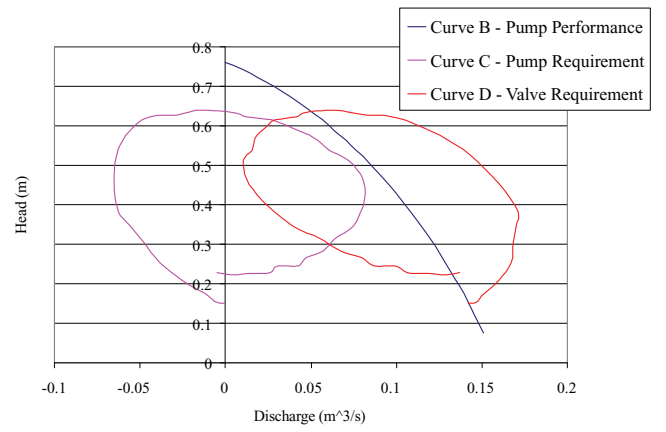

Figure 6. Vacuum pump performance curve, water flow requirement and valve requirement when generating the scaled Indian Ocean Tsunami wave. the Indian Ocean off Thailand by the Belgian yacht "Mercator". The original trace showed the seabed level relative to water level, so needed to be inverted to give the water surface, see Figure 5.

The Phase 2 calculations were therefore run for this time series at scales between 1:75 and 1:150.

For the design of the Tsunami Generator tank and control system, an empirical model was created to estimate flow rates, pressures and valve speeds in the tsunami generator based on methodologies described previously by Wilkie \& Young (1952), shown below Figure 6.

This procedure then gave the required performance envelope for the pump and control system shown in Figure 6. The left-hand loop in Figure 6 shows the required water head and flow rate to generate a typical scaled tsunami. The single curve shows the performance of an example pump, and it is important that this lies outside/above the demand loop. Then the righthand loop shows the resultant air valve requirement, assuming that air flow through the valve equals air flow out through the pump minus water flow out of the outlet. (It is noted that there will be an additional air flow requirement as part of the safety margin for the system, but that is dealt with separately.)

\subsection{Shallow water wave modelling}

The tsunami generator will propagate a given tsunami shape along the flume. At the scales considered, the approach slope in the test flume will represent the last 2 to $5 \mathrm{~km}$ of the prototype nearshore area. In most practical cases however, tsunami waves are generated at much greater distances from the coast. So the first stages of wave propagation need to be analysed using numerical models. In this project this is being carried out using ANEMONE (Brocchini \& Dodd, 2008) and/ or OXBOW (Borth-wick et al, 2006). A simplified configuration used in that modelling is shown in Figure 7.

\subsection{CFD modelling}

Having completed the initial empirical analysis and wave modelling discussed above, a more advanced

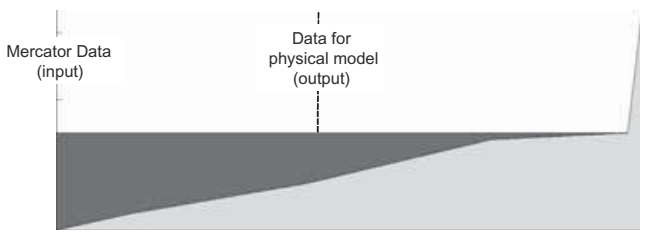

Figure 7. Configuration used for NLSW model used to propagate Tsunami waves from the yacht Mercator. 
CFD model was run to study detailed flows within the Tsunami Generator tank and the test flume. As water is sucked in and out of the tank, it is probable that local sloshing may be generated. Baffles have been placed within the tank to dampen this oscillation, but might reduce the peak flow rates. The CFD model includes water in the tank and in the test flume, and it uses the valve and pump pressure responses to predict water level changes in the tank as the tsunami is generated.

The results of the CFD modelling were analysed to check the main flow characteristics, determine the degree of seiching and consequently confirm the effectiveness of the baffles.

\section{FINAL DESIGN}

The preparatory analysis discussed above was then used to refine the final design of the tank and control system. The tank is being made from flanged and coated steel panels that were bolted together in sections. This allows modular construction, easy removal and storage. Bracing of the panels is required to avoid

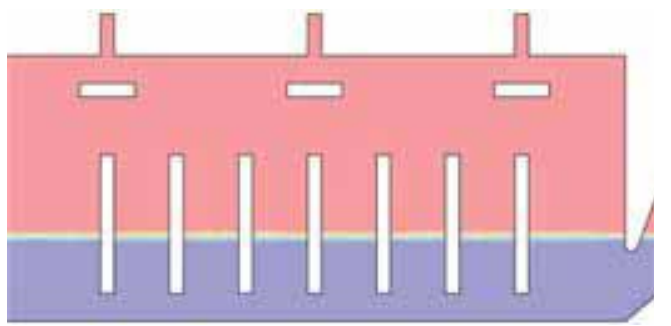

Figure 8. Schematic of the CFD model used to estimate flows/sloshing within the tank.

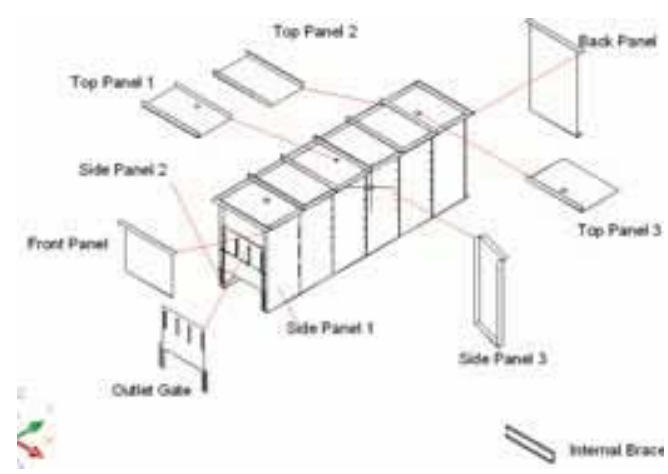

Figure 9. Tsunami Generator tank design. breakage or distortion of the tank during operation due to the pressure differences that build up between the inside and outside of the tank.

\section{DESIGN OF EXPERIMENTS}

The initial experiments that to be performed with the Tsunami Generator will be designed to validate the Tsunami Generator performance against available test cases, probably including:

- Solitary wave run-up (Synolakis CE., 1987)

- "N" waves (Tadepalli \& Synolakis, 1996)

The next stage, once validation is complete, will be to test the example from the 2004 Indian Ocean Tsunami, see Figure 5. A unique amount of data was gathered, giving wave characteristics, impact and runup at different locations around the world.

The main data to be used will be the Mercator time series. The Mercator was anchored a few kilometres off the coast of Thailand at the time of the Indian Ocean Tsunami. It recorded the variations in water depth as the tsunami passed beneath it with an echosounder (1' sampling interval). When inverted, this signal gives the surface elevation of the water on which Mercator was floating. The signal is relatively free from near-coastal effects and is therefore rather more useful than records from traditional tide gauges, all of which "drowned-out". This time sequence will probably be the main prototype event tested, although other wave profiles may be inferred from offshore data if they can be analysed and propagated (as described in section 4.2) to provide further input for the generator.

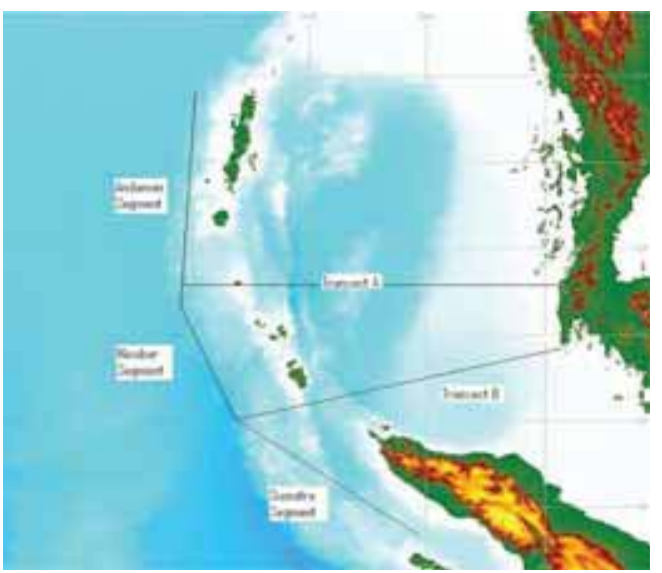

Figure 10. Wave directions, transects. 


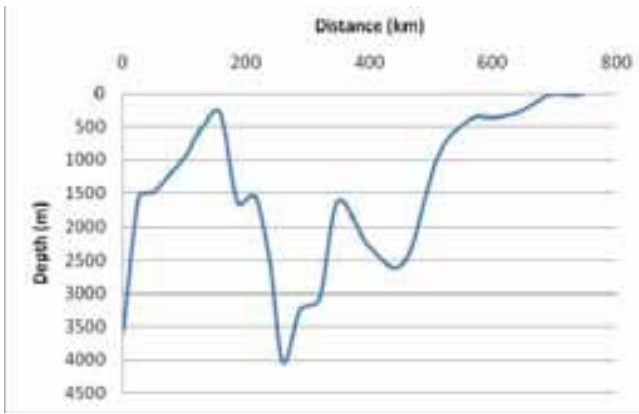

Figure 11. Transect A, source to Ban Thung Dap.

The initial test location adopted in the outline design of the experiments is therefore the western coast of Thailand, This is relatively close to the seismic source, so typical propagation effects affecting a tsunami generated a long distance away (effects of dispersion, Coriolis, earth curvature etc.,) are minimal. Moreover, at this point, the shoreline is approximately "parallel" to the source, so that it faces one of the most energetic propagation paths of the tsunami and allows realistic simplifications to be made as regards the most probable wave directions.

Two transects have been drawn and are shown in Figure 10 (with the seismic source outline-west). The bathymetry has been determined from the 1' grid GEBCO bathymetric data. Transect A (Figures $10 \& 11$ ) links the source to Ban Thung Dap (in Northern Thailand), where the largest wave height of about $20 \mathrm{~m}$ was recorded. Transect B in Figure 10 links the source to the Mercator location.

Some tsunami height data have been collected in South Phuket, for example in Kamala Beach and Pa-tong Beach. At a global scale, the probable wave propagation direction to reach Kamala and Patong is very similar to the wave propagation direction to the Mercator, so the same bathymetric profile can be inferred.

So, equivalent Mercator locations proposed around Phuket have been deduced by observing that the most probable wave path from the source to the Mercator is Transect B. This transect is approximately perpendicular to the Nicobar Segment. So if the distance separating the Sumatra junction from the Mercator is $630.7 \mathrm{~km}$, any wave created on the Nicobar segment and propagating towards the shore with a direction parallel to transect $\mathrm{B}$ will be a time series similar to the Mercator $630.7 \mathrm{~km}$ away from the source. In other words, any spatial line perpendicular to transect B passing through the original Mercator location should host a similar wave profile.

Refining the proposed experiment design will therefore require us to propagate numerically a typical

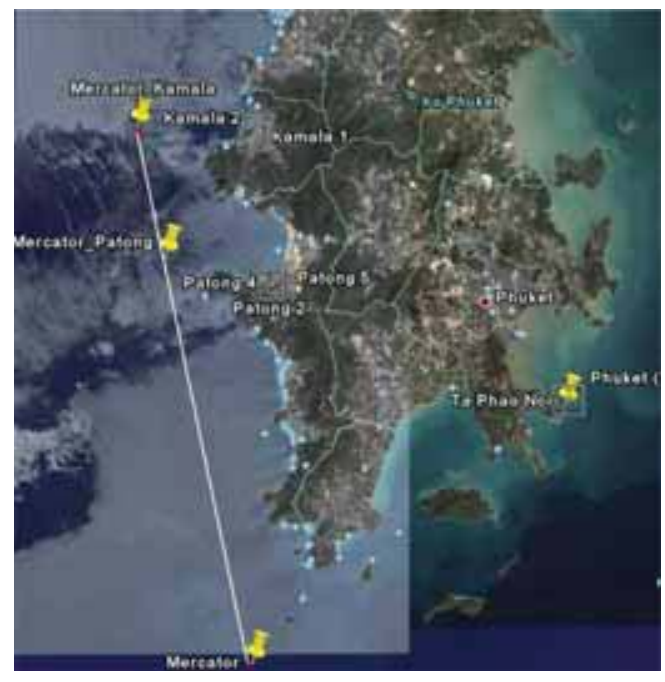

Figure 12. Line perpendicular to wave direction, Mercator and equivalent locations along Phuket (map courtesy of Google Maps).

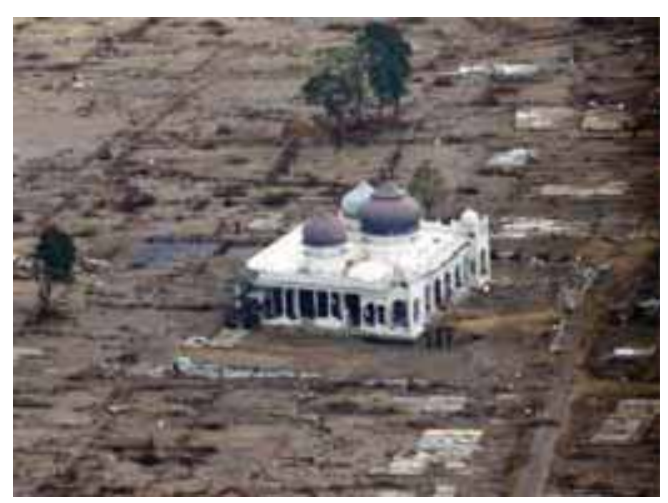

Figure 13. Tsunami Resistant Mosque.

tsunami from the source, or the Mercator time series, until it reaches a distance 2 to $5 \mathrm{~km}$ offshore. In this way we can obtain an input time series that will be physically propagated in the wave flume to simulate the effects observed on areas of the Thai coast such as Ban Thung Dap, Kamala or Patong. Very shallow nearshore bathymetries will be considered, as they are more representative of Thailand. The experiment data (runup, wave heights, velocities) will then be compared to collected data (e.g. from Rossetto et al. 2007).

Tsunami wave impacts on structures will also be assessed in the physical experiments. This involved scaled models of typical buildings being placed 


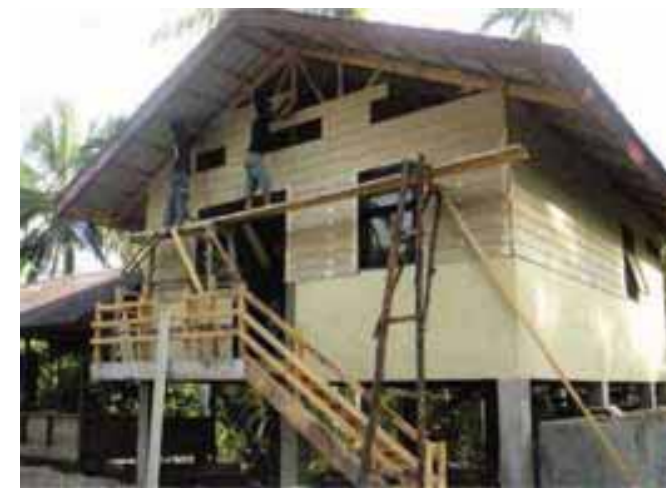

Figure 14. New Indonesian Tsunami-proof house.

within the flume and impact pressures and/or whole body forces being measured. At the initial stages of experiment design, it is proposed that three main structural types will be tested:

1. newly designed "tsunami-proof" buildings,

2. reinforced concrete moment resisting frames with and without infill walls (typical of hotel and government buildings),

3. proven tsunami resistant pillar structures (e.g. similar to the mosque in Banda Aceh, Indonesia in Figure 13).

Through these experiments, we aim to quantifying tsunami wave impacts on structures in relation to a typical tsunami parameter, perhaps also assessing the validity of existing design guidance (e.g. FEMA 55).

\section{FUTURE PLANS}

Construction and initial testing of the Tsunami Generator is intended to be completed in Summer 2008. Once proving trials are complete, then the EPICentre team will be using the facility to perform their experimental studies until November 2008.

It is intended that this facility will then become available for international teams to use, probably during a "slot" in autumn 2009.

\section{ACKNOWLEDGEMENTS}

The authors of this paper would like to thank all the members of the EPICentre team and Advisory Panel including Zygmunt Lubkowski, from ARUP, and Dr. Helene Joffe, Professor John Adams and Professor Nick Tyler from UCL. They would also like to thank the Engineering and Physical Sciences Research Council (EPSRC) for funding the EPICentre.

Further acknowledgement goes to Dr. Stephen Richardson, Mervyn Littlewood and Clive Rayfield from HR Wallingford for their assistance in the original development and detailed design of the tsunami generator.

\section{REFERENCES}

Borthwick AGL., Ford M., Weston BP., Taylor PH. and Stansby PK. Solitary wave transformation, breaking and run-up at a beach Maritime Engineering 159 Issue MA3 September 2006 Pages 97-105.

Brocchini M. and Dodd N. (2008) Nonlinear Shallow Water Equation Modelling for Coastal Engineering Journal of Waterway, Port, Coastal and Ocean Engineering Mar/Apr 2008.

Goring DG. (1978) Tsunamis-the propagation of long waves onto a shelf W M Keck Laboratory of Hydraulics and Water Resources 1978 Jan 1;(Report KH-R-38).

Hammack JL. (1972) Tsunamis-Amodel for their generation and propagation W M Keck Laboratory of Hydraulics and Water Resources 1972 Jan 1; (Report Kh-R-28).

RossettoT., Peiris N., Pomonis A., Wilkinson SM., Del Re D., Koo R. and Gallocher S. (2007) The Indian Ocean Tsunami of December 26, 2004: Observations in Sri Lanka and Thailand. Natural Hazards. 42 (1); 105-124.

Synolakis CE. (1987) The Runup of Solitary Waves, Journal of Fluid Mechanics 1987 Jan 1;185:523-45.

Tadepalli S. and Synolakis CE. (1996) Model for the Leading Waves of Tsunamis Physical Review Letters 77(10) Sept 1996, The American Physical Society

Wiegel RL. (1960) A presentation of cnoidal wave thory for practical application Journal of Fluid Mechanics 1960 Jan 1;7:273-86.

Wilkie MJ. and Young GAJ. (1952) Pneumatic Tide Generator The Engineer, July 1952. 


\title{
Fluid thinking...smart solutions
}

HR Wallingford provides world-leading analysis, advice and support in engineering and environmental hydraulics, and in the management of water and the water environment. Created as the Hydraulics Research Station of the UK Government in 1947, the Company became a private entity in 1982, and has since operated as a independent, non profit distributing firm committed to building knowledge and solving problems, expertly and appropriately.

Today, HR Wallingford has a 50 year track record of achievement in applied research and consultancy, and a unique mix of know-how, assets and facilities, including state of the art physical modelling laboratories, a full range of computational modelling tools, and above all, expert staff with world-renowned skills and experience.

The Company has a pedigree of excellence and a tradition of innovation, which it sustains by re-investing profits from operations into programmes of strategic research and development designed to keep it - and its clients and partners - at the leading edge.

Headquartered in the UK, HR Wallingford reaches clients and partners globally through a network of offices, agents and alliances around the world.

\section{HR Wallingford}

Working with water

\author{
HR Wallingford Ltd \\ Howbery Park \\ Wallingford \\ 0xfordshire 0X10 8BA \\ UK
tel $\quad+44(0) 1491835381$
fax +44 (0)1491832233
email info@hrwallingford.co.uk

\section{www.hrwallingford.co.uk}

